\begin{tabular}{|c|l|}
\hline Title & $\begin{array}{l}\text { In situ observation of photocatalytic reaction by photoacoustic spectroscopy : Detection of heat of exothermic } \\
\text { photocatalytic reaction }\end{array}$ \\
\hline Author(s) & Murakami, Naoya; A be, Ryu; Ohtani, Bunsho \\
\hline Citation & $\begin{array}{l}\text { Chemical Physics Letters, 451/46), 316-320 } \\
\text { https://doi.org/10.1016/.cplett.2007.12.014 }\end{array}$ \\
\hline Issue Date & 2008-01-21 \\
\hline Doc URL & http://hdl.handle.net/2115/33778 \\
\hline Type & article (author version) \\
\hline File Information & HET 2008.pdf \\
\hline
\end{tabular}

Instructions for use 


\title{
In-situ observation of photocatalytic reaction by photoacoustic spectroscopy: Detection of heat of exothermic photocatalytic reaction
}

\author{
Naoya Murakami, ${ }^{\mathrm{a}}$ Ryu Abe, ${ }^{\mathrm{a}, \mathrm{b}}$ Bunsho Ohtania, ${ }^{\mathrm{a},{ }^{*}}$ \\ ${ }^{a}$ Graduate School of Environmental Earth Science, Hokkaido University, Sapporo 060-0810, Japan \\ ${ }^{\mathrm{b}}$ Catalysis Research Center, Hokkaido University, Sapporo 001-0021, Japan
}

Received 27 July 2007; in final form 6 December 2007

\begin{abstract}
Modulation-frequency dependent photoacoustic (PA) spectroscopy was applied to gold-deposited titanium(IV) oxide powders in the presence of adsorbed methanol in order to detect the PA signal owing to phenomena occurring during photocatalytic reactions, e.g., release of reaction heat. Analysis of peak frequency of Helmholtz resonance provided qualitative information on changes in gas composition induced by photocatalytic reactions (oxidation or dehydrogenation of methanol), which depended on the presence or absence of oxygen. The PA signal attributable to heat of photocatalytic reaction was observed by canceling the effect of changes in gas composition using two kinds of modulated light as excitation and non-excitation for photocatalytic reaction.
\end{abstract}

* Corresponding author. FAX: +81-11-706-9133.

E-mail address: ohtani@cat.hokudai.ac.jp (B. Ohtani). 


\section{Introduction}

Titanium(IV) oxide $\left(\mathrm{TiO}_{2}\right)$ has been extensively investigated as one of the most promising candidates of a semiconductor photocatalyst and has been found to be suitable for a wide range of applications, such as oxidative decomposition of organic contaminants under ultraviolet (UV) irradiation [1]. For the improvement of efficiency and successful application of $\mathrm{TiO}_{2}$ photocatalysts, elucidation of the reactions taking place on the surface of a photocatalyst is of essential importance. A great deal of effort has so far been made on in-situ observation of reactions on a $\mathrm{TiO}_{2}$ surface under UV irradiation. Since UV irradiation often obstructs in-situ observation by spectroscopic techniques, electronic spectroscopy has seldom been used, and spectroscopic techniques in another energy region have been developed. For example, multiple internal reflection infrared spectroscopy has enabled in-situ observation of chemical reactions taking place over a $\mathrm{TiO}_{2}$ photocatalyst under simultaneous UV irradiation, though this technique requires film samples because of limitation of the spectroscopy [2]. In addition to these vibrational spectroscopic studies, direct observation, if possible, of the heat released by photocatalytic reaction would certainly provide useful information for further understanding of photocatalysis, though, as far as we know, no such studies have so far been reported.

We have recently applied photoacoustic spectroscopy (PAS) [3], one of the photothermal spectroscopic techniques, for in-situ observation of trivalent titanium species 
$\left(\mathrm{Ti}^{3+}\right)$ produced in $\mathrm{TiO}_{2}$ powder samples under continuous UV irradiation [4], and found a significant relationship between the properties of $\mathrm{Ti}^{3+}$ species and the photocatalytic activities of $\mathrm{TiO}_{2}$ samples [5]. In PAS, photoabsorption of materials is analyzed by photothermal waves, i.e., acoustic sounds generated by the relaxation process of photoexcited states, e.g., recombination of electron-hole pairs in semiconductor photocatalysts. Although the photoacoustic (PA) waves may mainly consist of the component due to deexcitation, e.g., electron-hole recombination, they are expected to include other components such as reaction heat when an exothermal photocatalytic reaction proceeds under appropriate reaction conditions [3]. In other words, intensity of the PA signal is expected to increase when an exothermal reaction proceeds on the photocatalyst. Furthermore, the gas evolution or consumption during a photocatalytic reaction causing increase in gas pressure possibly enhances PA response, and actually Gray and Bard have reported such PA signal change due to the gas evolution by a platinized $\mathrm{TiO}_{2}$ photocatalyst [6]. However, all of these components are included in a PA wave and detected at the same time by a microphone. In order to analyze these components individually, they have to be extracted. One possible method is modulation-frequency dependent measurement that can divide multiple components depending on their different frequency responses toward modulated photoexcitation. For example, it has been reported that the recombination process in $\mathrm{TiO}_{2}$ proceeds in a time scale of picoseconds [7], which is sufficiently fast to follow high modulation frequency of 
photoexcitation. On the other hand, photocatalytic reactions generally have lower frequency response compared to the recombination, because of the subsequent reaction mechanism and the presence of activated intermediate species of relatively long lifetime.

In the present study, we applied modulation-frequency dependent PA measurements to photocatalytic reaction over gold-deposited $\mathrm{TiO}_{2}$ in the presence of methanol as a reactant in order to detect and analyze the reaction heat released during photocatalytic reaction. Gold-deposited $\mathrm{TiO}_{2}$ is suitable for the present measurement because the changes in photoabsorption due to photoproduced $\mathrm{Ti}^{3+}$ species could be neglected, and deposited-gold is inert for such dark reaction with methanol.

\section{Experimental}

\subsection{Preparation of gold-deposited $\mathrm{TiO}_{2}$ samples}

An aqueous suspension composed of $\mathrm{TiO}_{2}$ powders (P25, Nippon Aerosil) and a methanol solution $(50 \mathrm{vol} \%)$ containing tetrachloroauric acid $\left(\mathrm{HAuCl}_{4} \cdot 4 \mathrm{H}_{2} \mathrm{O}\right)$, the amount of which corresponds to $2 \mathrm{wt} \%$ loading of metallic gold (Au), was photoirradiated under an argon atmosphere with vigorous magnetic stirring. After irradiation, Au-deposited samples $\left(\mathrm{Au} / \mathrm{TiO}_{2}\right)$ were obtained by washing with water several times and drying.

\subsection{Modulation-frequency dependent PA measurements}


Modulation-frequency dependent PA spectra were recorded in the range of $10 \mathrm{~Hz}$ to $20 \mathrm{kHz}$, starting from $10 \mathrm{~Hz}$, with 100 data points. Acquisition of data at each frequency took $\approx 25 \mathrm{~s}$, and a spectrum was taken for at least $\approx 30 \mathrm{~min}$, and measurements were repeated with an appropriate interval. In displaying the time course of changes in PA signal, starting time (at $10 \mathrm{~Hz}$ ) is shown, and thereby a data point at $20 \mathrm{kHz}$ in the spectrum for 40 min is taken at $\approx 70$ min measured from the starting time. A light-emitting diode (LED) with an emission peak at $365 \mathrm{~nm}$ (Nichia, NCCU033) was used as probe and excitation light $\left(1.0 \mathrm{~mW} \mathrm{~cm} \mathrm{~cm}^{-2}\right)$, and its output intensity was sine-modulated by a digital function generator (NF, DF1905). An LED with an emission peak at $455 \mathrm{~nm}$ (Luxeon, LXHL-NRR8) was also used as a standard probe light $\left(11 \mathrm{~mW} \mathrm{~cm}^{-2}\right)$ in addition to the $365-\mathrm{nm}$ LED. The PA signal was normalized by light intensity of each LED. When these two LEDs were used, a sample was irradiated at $455 \mathrm{~nm}$ and then at $365 \mathrm{~nm}$ with a given modulation frequency. Atmosphere was controlled by the flow of nitrogen $\left(\mathrm{N}_{2}\right)$ or oxygen $\left(\mathrm{O}_{2}\right)$ containing methanol vapor $\left(\mathrm{N}_{2}+\mathrm{CH}_{3} \mathrm{OH}, \mathrm{O}_{2}+\mathrm{CH}_{3} \mathrm{OH}\right.$; atmospheric pressure), and the measurements were carried out in a closed system at room temperature. Detailed setups of PAS measurements have been reported $[4,5]$.

\section{Results and discussion}

\subsection{PA gas sensing by Helmholtz resonance}


It is known that the PA signal is significantly influenced by the composition of gas phase through which PA waves propagate to reach a microphone. Therefore, we measured in the first step the modulation-frequency dependent PA spectra of carbon black powder (CBP), which induces no photocatalytic reaction, in various gas phases in order to evaluate the influence of gas composition on PA spectra independently from photocatalytic reaction. Figure 1a shows modulation-frequency dependent PA spectra of CBP under atmospheres of pure carbon dioxide $\left(\mathrm{CO}_{2}\right), \mathrm{N}_{2}$, methane $\left(\mathrm{CH}_{4}\right)$, helium $(\mathrm{He})$, and hydrogen $\left(\mathrm{H}_{2}\right)$ under modulated photoirradiation at $455 \mathrm{~nm}$. Two sharp peaks in a high-frequency region $(0.4-2$ and $2.5-10 \mathrm{kHz}$ ) were observed in all cases, and the peak position strongly depended on the atmosphere. These sharp peaks in the high-frequency region are attributable to Helmholtz resonance, which is known as a phenomenon of acoustic resonance in a cavity. According to the theory on generation and propagation of PA waves, which has been established by Kreuzer [8], resonance frequency, $f_{R}$, is a function with specific heat ratio of gas, $\gamma$, and average molecular weight, $M_{\mathrm{w}}$, as follows:

$$
f_{\mathrm{R}} \propto\left(\gamma / M_{\mathrm{w}}\right)^{1 / 2}
$$

A linear relationship was found between peak frequency in the highest-frequency region $(2.5-10 \mathrm{kHz})$ evaluated from the curves in Fig. 1a and $\left(\gamma / M_{\mathrm{w}}\right)^{1 / 2}$ values calculated for each gas (Fig. 1b), indicating that the peaks in the highest-frequency region are actually due to Helmholtz resonance. These results suggest that peak frequency can be used as a 
semiquantitative measure for gas components in the reaction cells.

\subsection{Evaluation of photocatalytic reaction by PA gas sensing}

We next examined change in $\mathrm{PA}$ spectra using an $\mathrm{Au} / \mathrm{TiO}_{2}$ photocatalyst during photoirradiation with a wavelength of $355 \mathrm{~nm}$, which induces photoexcitation of $\mathrm{TiO}_{2}$, in the presence of methanol vapor in the PAS cell. Since preliminary experiments using platinized $\mathrm{TiO}_{2}$ showed that oxidation of methanol occurs in the dark, $\mathrm{Au} / \mathrm{TiO}_{2}$ was employed. Figure 2 shows modulation-frequency dependent spectra of $\mathrm{Au} / \mathrm{TiO}_{2}$ (a) in the absence of $\mathrm{O}_{2}$ $\left(\mathrm{N}_{2}+\mathrm{CH}_{3} \mathrm{OH}\right)$ and (b) in the presence of $\mathrm{O}_{2}\left(\mathrm{O}_{2}+\mathrm{CH}_{3} \mathrm{OH}\right)$. In these spectra, the peaks attributable to Helmholtz resonance shifted appreciably during photoirradiation. Such a frequency shift was observed only when the $\mathrm{Au} / \mathrm{TiO}_{2}$ photocatalyst was irradiated by light of energy greater than the band gap of $\mathrm{TiO}_{2}(\lambda<400 \mathrm{~nm})$ in the presence of methanol. These results indicate that photocatalytic reactions changed the gas composition. The frequency of resonance peaks in the highest-frequency region $\left(f_{\mathrm{p}}\right)$ is plotted against the time of photoirradiation in Fig. 3. In the absence of $\mathrm{O}_{2}$, the frequency increased monotonically with irradiation time. It is most probable that methanol dehydrogenation takes place over a metal-deposited $\mathrm{TiO}_{2}$ photocatalyst in the absence of $\mathrm{O}_{2}$ as follows [7].

$$
\mathrm{CH}_{3} \mathrm{OH} \rightarrow \mathrm{HCHO}+\mathrm{H}_{2}
$$

In this case, progress of the photocatalytic reaction results in a decrease of $M_{\mathrm{w}}$ due to the 
release of low-molecular-weight products, $\mathrm{H}_{2}$, which can reasonably explain the monotonic increase of resonance frequency seen in Fig. 3. On the other hand, $f_{\mathrm{p}}$ decreased in the initial stage and then increased in the presence of $\mathrm{O}_{2}$, as shown in Fig. 3. It is expected that the photocatalytic stepwise oxidation of methanol proceeds in the presence of $\mathrm{O}_{2}$ as follows:

$$
\begin{aligned}
& \mathrm{CH}_{3} \mathrm{OH}+\frac{1}{2} \mathrm{O}_{2} \rightarrow \mathrm{HCHO}+\mathrm{H}_{2} \mathrm{O} \\
& \mathrm{HCHO}+\frac{1}{2} \mathrm{O}_{2} \rightarrow \mathrm{HCOOH} \\
& \mathrm{HCOOH}+\frac{1}{2} \mathrm{O}_{2} \rightarrow \mathrm{CO}_{2}+\mathrm{H}_{2} \mathrm{O}
\end{aligned}
$$

Among the intermediates and final products, $\mathrm{H}_{2} \mathrm{O}, \mathrm{HCOOH}$ and $\mathrm{CH}_{3} \mathrm{OH}$ have relatively high boiling points $\left(\mathrm{CH}_{3} \mathrm{OH}: 65{ }^{\circ} \mathrm{C}, \mathrm{H}_{2} \mathrm{O}: 100{ }^{\circ} \mathrm{C}, \mathrm{HCOOH}: 101{ }^{\circ} \mathrm{C}\right)$ compared with those of others $\left(\mathrm{HCHO}, \mathrm{O}_{2}\right.$, and $\left.\mathrm{CO}_{2}<0{ }^{\circ} \mathrm{C}\right)$. Therefore, we can expect that the amounts of $\mathrm{CH}_{3} \mathrm{OH}$, $\mathrm{H}_{2} \mathrm{O}$ and $\mathrm{HCOOH}$ in gas phase are negligibly small and rarely affect the Helmholtz resonance in the present experiments carried out at room temperature. Based on this consideration, increase in $M_{\mathrm{w}}$ can be ascribed to liberation of a relatively high-molecular-weight product, $\mathrm{CO}_{2}$. As shown in Fig. 3, $f_{\mathrm{p}}$ decreased in the initial stage and reached a minimum value of 2.6 $\mathrm{kHz}$, which is close to the theoretical value of $2.55 \mathrm{kHz}$ calculated using $M_{\mathrm{w}}$ of 44 . Therefore, the decrease in $f_{\mathrm{p}}$ in the initial stage is accounted for by the progress of photocatalytic oxidation of methanol into $\mathrm{CO}_{2}$ and $\mathrm{H}_{2} \mathrm{O}$ accompanied by $\mathrm{O}_{2}$ consumption. After complete consumption of $\mathrm{O}_{2}$ in a cell, only photocatalytic dehydrogenation of methanol (Eq. (2)), decreasing $M_{\mathrm{w}}$, proceeds over $\mathrm{Au} / \mathrm{TiO}_{2}$, resulting in increase in $f_{\mathrm{p}}$ as was observed in 
the measurement under $\mathrm{N}_{2}+\mathrm{CH}_{3} \mathrm{OH}$. The evolution of $\mathrm{CO}_{2}$ and consumption of $\mathrm{O}_{2}$ in the initial stage and the evolution of $\mathrm{H}_{2}$ in the subsequent stage were confirmed by analysis of gas phase in the cell by gas chromatography. These results indicate that the frequency shift of the Helmholtz resonance peak can be used for in-situ detection of changes in gas composition in the course of photocatalytic reactions, though it is rather qualitative.

\subsection{PA detection of heat due to exothermic photocatalytic reaction}

The modulation-frequency dependent PA spectra shown in Fig. 2 might include information on photocatalytic reactions themselves, e.g., reaction heat, as well as gas evolution/consumption and changes in photoabsorption of a photocatalyst. In the present study, the changes in photoabsorption could be neglected as reported previously [4]; actually, negligible time-course change in PA intensity was observed at each modulation frequency. As mentioned above, the changes in gas composition in the cell during photocatalytic reaction significantly affect the modulation-frequency dependent PA spectra not only in the frequency of peaks but also in their signal intensity. We attempted to extract information attributable to photocatalytic reaction from the PA spectra by applying alternating modulated photoirradiation (12 s each) at the wavelengths of 365 and $455 \mathrm{~nm}$ for photoexcitation of $\mathrm{Au} / \mathrm{TiO}_{2}$ to drive photocatalytic reaction and for compensation of the changes in gas composition, respectively. 
It has been confirmed that negligible photocatalytic reaction proceeds over $\mathrm{Au} / \mathrm{TiO}_{2}$ by photoirradiation at $455 \mathrm{~nm}$. Therefore, we can evaluate the information arising from photocatalytic reaction independently by using the value $R$, the ratio of PA intensity with irradiation at $365 \mathrm{~nm}\left(I_{365}\right)$ to that at $455 \mathrm{~nm}\left(I_{455}\right), R=I_{365} / I_{455}$. The intensity of the PA signal at $365 \mathrm{~nm}\left(I_{365}\right)$ is governed by three components related to heat of the reaction, heat due to deexcitation, and gas evolution/consumption, both of which are influenced by the change in gas composition, while $I_{455}$ contains only the component of deexcitation depending on the gas composition similar to the PA response at $365 \mathrm{~nm}$. Therefore, it is expected that an $R$ spectrum shows PA response without influence of changes in gas composition. Because each component has respective frequency response depending on the mechanism of generation and propagation of the PA wave from them as mentioned in Sec. 3.1, the variation of modulation frequency enables analysis of each component independently.

Figure 4 shows $R$ spectra of an $\mathrm{Au} / \mathrm{TiO}_{2}$ sample (a) in the absence of $\mathrm{O}_{2}$ $\left(\mathrm{N}_{2}+\mathrm{CH}_{3} \mathrm{OH}\right)$ and (b) in the presence of $\mathrm{O}_{2}\left(\mathrm{O}_{2}+\mathrm{CH}_{3} \mathrm{OH}\right)$ under alternating irradiation of modulated light of wavelengths at 356 and $455 \mathrm{~nm}$. The shift in the spectra in both cases during the initial stage of measurement $(<40 \mathrm{~min})$ clearly indicates that time for the system to reach a thermal steady state was needed, since it was observed regardless of atmosphere $\left(\mathrm{N}_{2}\right.$ or $\mathrm{O}_{2}$ ). In the absence of $\mathrm{O}_{2}$, no appreciable change was observed in $R$ spectra during the measurements involving band-gap excitation of $\mathrm{TiO}_{2}(>40 \mathrm{~min})$. On the other hand, the $R$ 
spectra clearly shifted downward in the initial period $(<255 \mathrm{~min})$ in the presence of $\mathrm{O}_{2}$, especially at a lower frequency region, and were almost the same at $>255 \mathrm{~min}$. This behavior seems to be closely related to the gas composition shown in Fig. 1, indicating that methanol oxidation proceeded in the initial period $(<255 \mathrm{~min})$ and then methanol dehydrogenation took place after almost complete consumption of $\mathrm{O}_{2}$ in the cell also under the conditions of the measurements. Therefore, the reduction of $R$ in the presence of $\mathrm{O}_{2}$ is attributable to the photocatalytic oxidation of methanol over $\mathrm{Au} / \mathrm{TiO}_{2}$. As described in preceding sections, only the PA response due to the recombination process may follow high modulation of irradiation, and, therefore, the observed downward shift, i.e., increase in the PA signal in a lower frequency region, is possibly attributed to reaction heat and/or gas evolution/consumption induced by the photocatalytic reaction. As for the effect of gas evolution/consumption on the PA signal, it is expected that PA intensity increases and decreases corresponding to gas evolution and consumption, respectively [9]. The methanol oxidation in the presence of $\mathrm{O}_{2}$ and dehydrogenation in the absence of $\mathrm{O}_{2}$ result in $0.5-\mathrm{mol}$ gas consumption and 1-mol gas evolution, respectively, which seem opposite to the results. On the other hand, it is calculated that the oxidation and dehydrogenation of methanol are exothermic reaction $(\Delta H=+34.85 \mathrm{~kJ}$ $\left.\mathrm{mol}^{-1}\right)$ and endothermic reaction $\left(\Delta H=-726.55 \mathrm{~kJ} \mathrm{~mol}^{-1}\right)$, respectively. Therefore, the difference in the changes of $R$ depending on the absence and presence of $\mathrm{O}_{2}$ can be explained considering the effect of reaction heat on PA response. 
The $R$ value in the low frequency region $(<100 \mathrm{~Hz})$ in the presence of $\mathrm{O}_{2}$ is clearly larger than that in the absence of $\mathrm{O}_{2}$ at the time of measurement $<255 \mathrm{~min}$, because the exothermic methanol oxidation proceeds in the presence of $\mathrm{O}_{2}$. Along with consumption of $\mathrm{O}_{2}$ in the cell, the rate of methanol oxidation slowed down, resulting in a decrease of exothermic heat and downward shift of $R$. It should be noted that an appreciable difference in the changes of $R$ spectra depending on the atmosphere was observed only at the low frequency region $<100 \mathrm{~Hz}$. This implies that intermediacy of relatively long-lived species of lifetime $>10 \mathrm{~ms}$ contributed only to the photocatalytic methanol oxidation. One of the possible candidates of such species is hydrogen peroxide or surface hydroperoxy species, though we have at present no experimental evidence. These results indicate that the present modulation-frequency dependent PAS can be used for estimation of the lifetime of intermediate species as well as the reaction heat of photocatalytic reactions.

\section{Conclusions}

Modulation-frequency dependent PAS enabled in-situ observation of photocatalytic reaction by detecting the PA signal due to heat of photocatalytic reaction, which was discriminated from the PA response owing to the recombination of electron-hole pairs and evolution/consumption of gases and corrected for the influence of changes in gas composition. Considering that the PA signal appeared only when the frequency of light modulation was 
below $\approx 100 \mathrm{~Hz}$, it is thought that the photocatalytic process of methanol oxidation releasing heat involves intermediate of relatively long lifetime. The present modulation-frequency dependent PAS is expected to be a useful tool for analysis of photocatalytic reaction and would provide new insights into photocatalytic reaction, especially for exothermic photocatalytic processes.

\section{Acknowledgments}

The authors gratefully acknowledge Professor Taro Toyoda (The University of Electro-Communications) for his help in the design of PAS setups. This work was supported by a Grant-in-Aid for Scientific Research on Priority Areas (417) from the Ministry of

Education, Culture, Sports, Science and Technology (MEXT) of the Japanese Government.

\section{References}

[1] M.R. Hoffmann, S.T. Martin, W. Choi, D.W. Bahnemann, Chem. Rev. 95 (1995) 69.

[2] R. Nakamura, A. Imanishi, K. Murakoshi, Y. Nakato, J. Am. Chem. Soc. 125 (2003) 7443.

[3] A.C. Tam, Rev. Mod. Phys. 58 (1986) 381.

[4] N. Murakami, O.O. Prieto Mahaney, T. Torimoto, B. Ohtani, Chem. Phys. Lett. 426 (2006) 204. 
[5] N. Murakami, R. Abe, O.O. Prieto Mahaney, T. Torimoto, B. Ohtani, Stud. Surf. Sci. Catal. 172 (2007) 429.

[6] R.C. Gray and A.J. Bard, Anal. Chem. 50 (1978) 1262.

[7] S. Ikeda, N. Sugiyama, B. Pal, B. Ohtani, H. Noguchi, K. Uosaki, G. Marci, L. Palmisano, Phys. Chem. Chem. Phys. 3 (2001) 267.

[8] L.B. Kreuzer, in: Y-H. Pao (Ed.), Optoacoustic Spectroscopy and Detection, Academic Press, New York, 1977.

[9] G. Bults, B.A. Horwitz, S. Malkin, D. Cahen, Biochim. Biophys. Acta. 679 (1982) 452. 


\section{Figure captions}

Fig. 1. (a) Modulation-frequency dependent PA spectra of CBP under various atmospheres $\left(\mathrm{CO}_{2}, \mathrm{~N}_{2}, \mathrm{CH}_{4}, \mathrm{He}, \mathrm{H}_{2}\right)$ with irradiation at $455 \mathrm{~nm}$ as modulated light. (b) Relationship between peak frequency in the highest-frequency region $(2.5-10 \mathrm{kHz})$ evaluated from the curves in Fig. 1a and $\left(\gamma / M_{\mathrm{w}}\right)^{1 / 2}$ values calculated for each gas.

Fig. 2. Modulation-frequency dependent $\mathrm{PA}$ spectra of $\mathrm{Au} / \mathrm{TiO} \mathrm{O}_{2}$ under (a) $\mathrm{N}_{2}+\mathrm{CH}_{3} \mathrm{OH}$ and (b) $\mathrm{O}_{2}+\mathrm{CH}_{3} \mathrm{OH}$ by using modulated light of $365 \mathrm{~nm}$.

Fig. 3. Time course of $f_{\mathrm{p}}$ obtained in modulation-frequency dependent PA spectra of $\mathrm{Au} / \mathrm{TiO}_{2}$ under $\mathrm{N}_{2}+\mathrm{CH}_{3} \mathrm{OH}$ and $\mathrm{O}_{2}+\mathrm{CH}_{3} \mathrm{OH}$.

Fig. 4. $R$ spectra of $\mathrm{Au} / \mathrm{TiO}_{2}$ under (a) $\mathrm{N}_{2}+\mathrm{CH}_{3} \mathrm{OH}$ and (b) $\mathrm{O}_{2}+\mathrm{CH}_{3} \mathrm{OH}$ by using modulated light of $365 \mathrm{~nm}$ as induction and $455 \mathrm{~nm}$. 


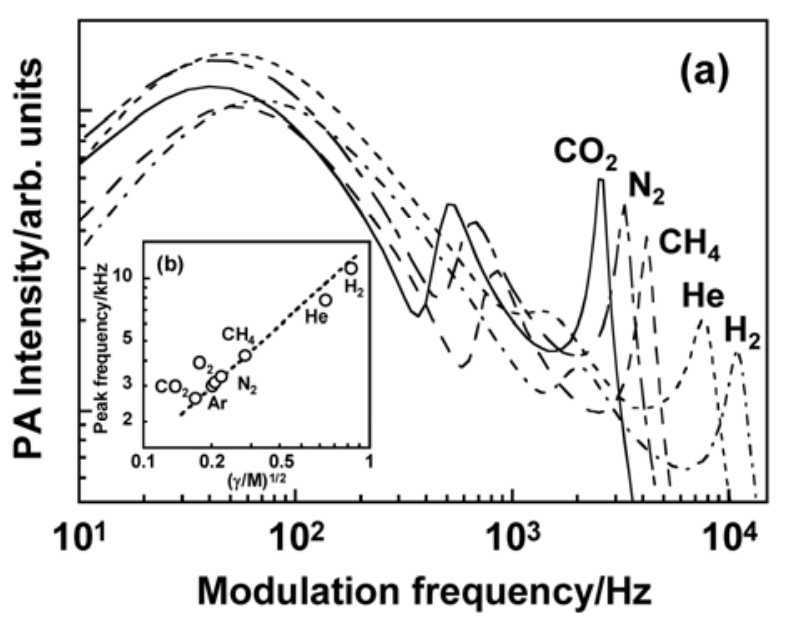

Fig. 1. Murakami et al. 

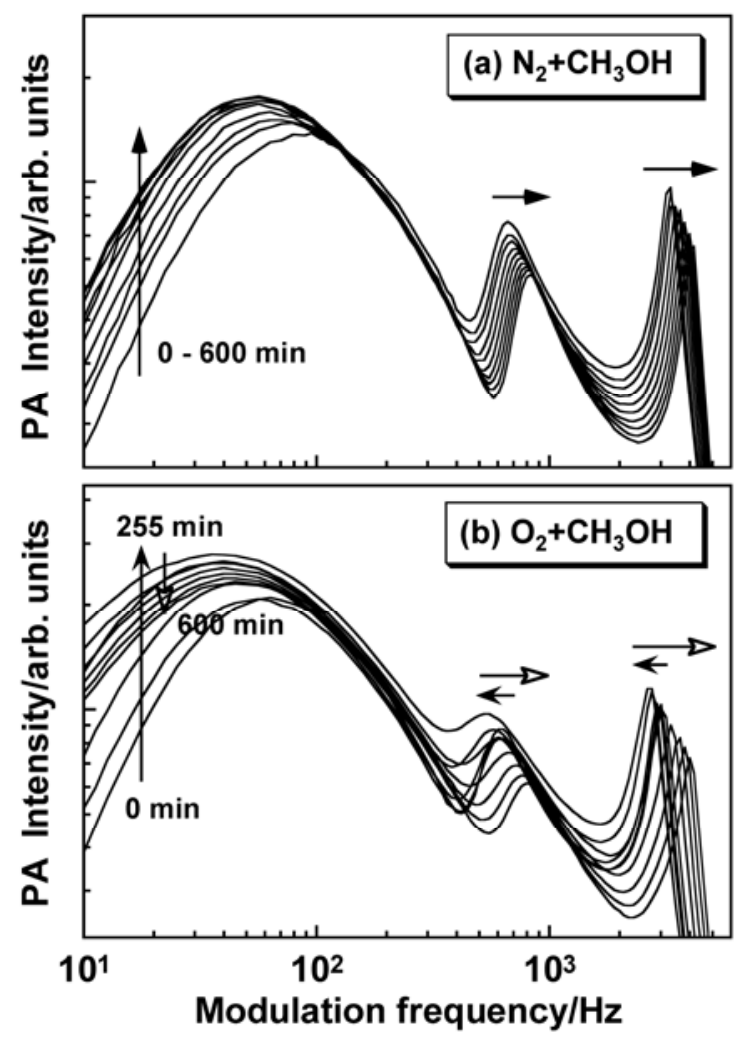

Fig. 2. Murakami et al. 


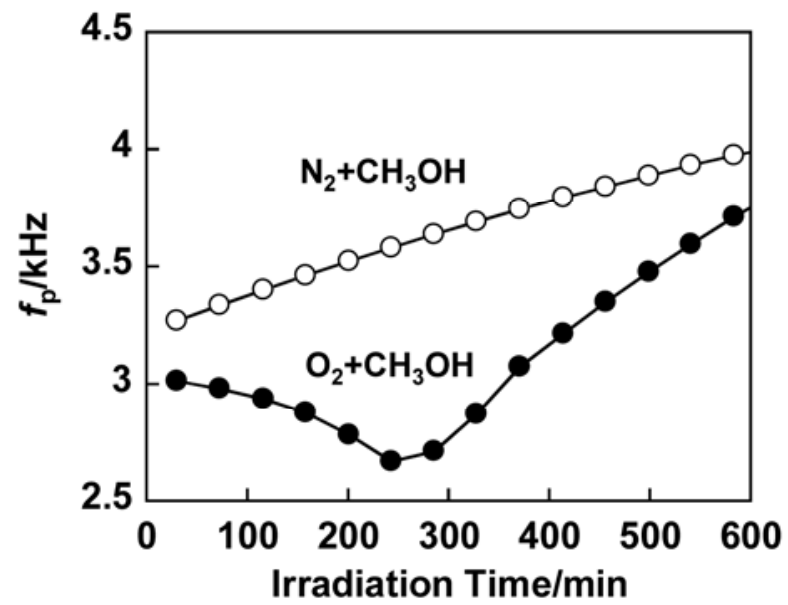

Fig. 3. Murakami et al. 


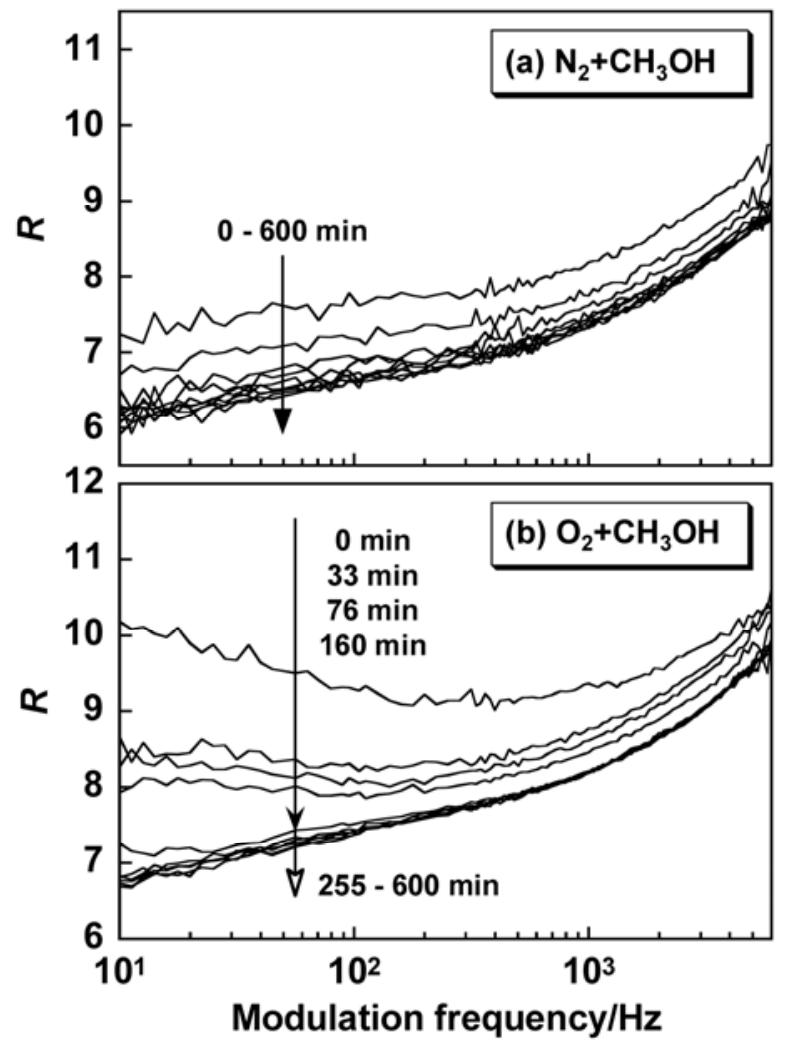

Fig. 4. Murakami et al. 


\section{Graphical Abstract}

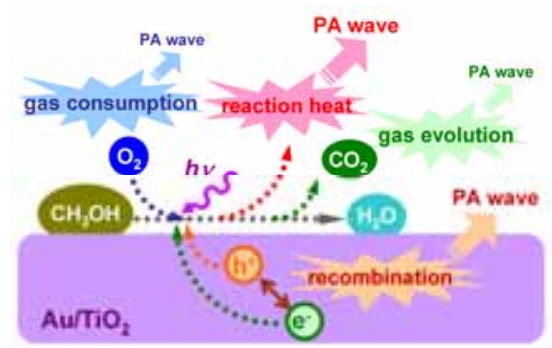

Modulation-frequency dependent photoacoustic spectroscopy enabled in-situ observation of

photocatalytic reaction by detecting the photoacoustic signal due to heat of photocatalytic reaction. 